\title{
Electro-oculographic abnormalities in amblyopia
}

\author{
C Williams, D Papakostopoulos
}

\begin{abstract}
Background-Electrodiagnostic tests have been used to investigate retinal function in amblyopia but previous results have been conflicting.

Methods-It was decided to investigate whether the electro-oculogram (EOG) showed any abnormalities in 12 adult amblyopes and 12 age and sex matched controls with normal vision. The mean amplitudes of the EOG recordings from each eye during 12 minutes of darkness and 18 minutes of light were compared.

Results-The mean values from the amblyopic eyes were lower than those from the fellow non-amblyopic eyes. At most time points the difference was significant $(p<0 \cdot 05)$. After normalisation of the data to minimise intersubject variation, the reduction in EOG amplitudes of the amblyopic eyes at all time points was significant $(p<0 \cdot 05)$. There was no significant difference between the mean values obtained from the right and left control eyes at any time point, either before or after normalisation.

Conclusion-These results provide evidence for a retinal abnormality in amblyopia and implicate the retinal pigment epithelium as being involved. A deficiency in retinal dopaminergic function in amblyopia is proposed as a possible mechanism causing these results.

(Brf Ophthalmol 1995; 79: 218-224)
\end{abstract}

Retinal function in amblyopia has previously been investigated using various techniques. Ikeda and Tremain demonstrated abnormal direct recordings from lateral geniculate nucleus (LGN) cells and from retinal ganglion cells in strabismic cats. ${ }^{12}$ Abnormal pattern electroretinograms (PERGs) in strabismic cats have been recorded, reduced in either phase or amplitude or both. ${ }^{34}$ In human amblyopia the PERG can also be reduced in amplitude. ${ }^{56}$ The amblyopes with reduced PERGs in their affected eyes were those who had failed to respond to occlusion whereas those who had responded to treatment had supranormal PERGs in their amblyopic eyes. ${ }^{7}$ However, other groups have not found significantly more interocular variation in the PERGs of amblyopes than in normal subjects. ${ }^{8-10}$

The electro-oculogram (EOG) is a test of retinal function, in which changes in the standing potential (SP) of the eye are made manifest. ${ }^{11-12}$ The SP of the mammalian eye is generated primarily by a potential difference between the apical and basal membranes of the retinal pigment epithelium (RPE). In darkness the potential falls to a trough value (the dark trough; DT). In response to light there is a dose dependent increase in the potential difference, developing over several minutes to a peak value (the light peak; LP) then slowly declining to basal levels. Dopamine has been implicated in the generation of the SP in animal studies ${ }^{13}$ and shown to affect the DT in normal human subjects. ${ }^{14}$ There is evidence that systemic dopamine can improve visual function in the elderly 15 and in amblyopic adults ${ }^{16}$ and children. ${ }^{17} 18$ It was therefore decided to investigate whether the EOG showed any abnormalities in amblyopic eyes compared with normal eyes.

\section{Materials and methods}

The amblyopic subjects were 12 anisometropic or strabismic adults with an interocular difference in visual acuity of at least 2 Snellen lines when wearing full refractive correction. The control subjects were 12 adults with full visual acuity in each eye. The two groups were balanced as far as possible regarding age and sex. All subjects had a full ophthalmic examination including visual field assessment and funduscopy to exclude any ocular disease. No subject was using systemic medication or eyedrops or had had previous ocular surgery. All subjects had normally aligned corneal reflections before dissociation by the prism cover test and had full eye movements. The EOG recordings were carried out by the same operator who was blind to the visual acuity results.

The subjects were seated 1.5 metres in front of a panel on which were mounted eight neon tube bulbs. Two small red bulbs served as fixation lights and were positioned across the centre of the screen such that a 30 degree movement of the eyes were necessary for the subject to change fixation from one to the other. Chlorided silver electrodes were attached to the bridge of the nose and at each outer canthus. An earth electrode was attached to one temple. The resistance of the electrodes was $<5 \mathrm{kOhm}$, measured with a $40 \mathrm{~Hz}$ resistance meter. The signals were amplified by an EEG machine (Dantec). The time constant was 10 seconds, the gain $200 \mu \mathrm{V} / \mathrm{cm}$, and the upper frequency response was $100 \mathrm{~Hz}(3 \mathrm{~dB}$ down). The subjects were instructed to make fast eye movements from one fixation point to the other at a rate of once a second. Eight such eye movements comprised a sequence. Sequences were then performed and recorded every 2 minutes. Six sequences were recorded in the dark after an initial 20 minute period of adaptation to room light (room light was 122 lux measured at the subject's face). The room and panel lights were then turned on (1000 lux measured at the subject's face) and 
Table 1 Clinical details of amblyopic subjects

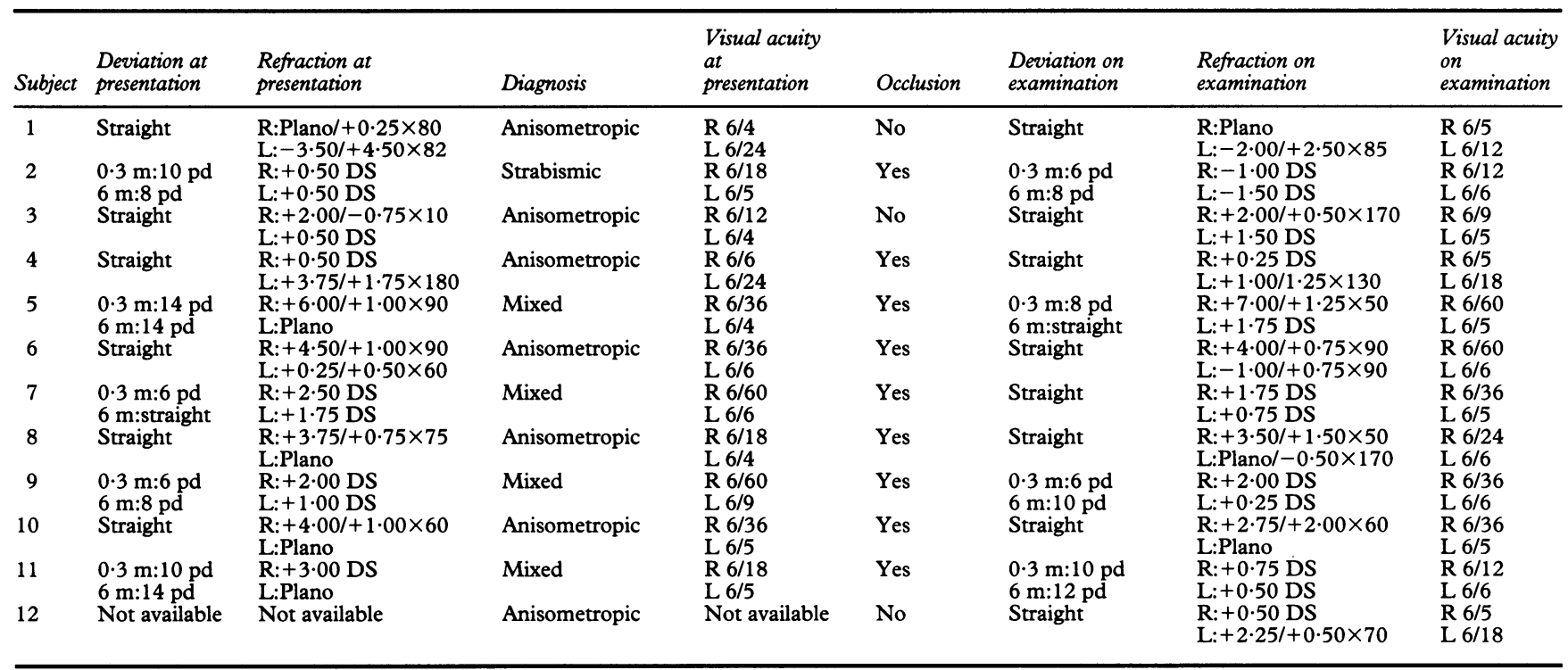

another nine sequences were recorded in the light. The amplitude of potential difference for each eye was measured. The head position, eye movements, and pupil diameter were all monitored using an infrared closed circuit TV camera. All results were analysed using the two tailed Student's $t$ test, paired or unpaired as appropriate. A p value of 0.05 or less was considered significant.

The clinical details of the amblyopic subjects are shown in Table 1 where 'mixed' denotes amblyopia associated with both anisometropia and strabismus. The details of the normal controls are shown in Table 2.

\section{Results}

Twelve adult amblyopes and 12 normal control subjects were examined. The amblyopes comprised eight females and four males; the controls were nine females and three males. The mean ages were 23.7 (SD 4.2 ) years for the amblyopes and 23.8 (SD 2.4) years for the normal controls. For each subject, 15 values were obtained from each eye, corresponding to the amplitude of potential recorded

Table 2 Clinical details of control subjects

\begin{tabular}{|c|c|c|c|}
\hline Name & Deviation & Refraction & Visual acuity \\
\hline 1 & Straight & $\begin{array}{l}\text { R: }-0.50 /+0.75 \times 160 \\
\text { L: }-0.5 /+1.00 \times 5\end{array}$ & $\begin{array}{l}\text { R 6/4 } \\
\text { L } 6 / 4\end{array}$ \\
\hline 2 & Straight & $\begin{array}{l}\text { R:Plano } \\
\text { L:Plano }\end{array}$ & $\begin{array}{l}\text { R } 6 / 5 \\
\text { L } 6 / 5\end{array}$ \\
\hline 3 & Straight & $\begin{array}{l}\text { R: }-3 \cdot 25 /+0 \cdot 75 \times 70 \\
\mathrm{~L}:-4 \cdot 50 /+1 \cdot 25 \times 160\end{array}$ & $\begin{array}{l}\text { R } 6 / 6 \\
\mathrm{~L} 6 / 6\end{array}$ \\
\hline 4 & Straight & $\begin{array}{l}\text { R: }-0.50 /+0.25 \times 60 \\
\text { L: }-0.50 /+0.50 \times 120\end{array}$ & $\begin{array}{l}\text { R } 6 / 5 \\
\text { L } 6 / 5\end{array}$ \\
\hline 5 & Straight & $\begin{array}{l}\mathrm{R}:-1 \cdot 25 \mathrm{DS} \\
\mathrm{L}:-1.25 \mathrm{DS}\end{array}$ & $\begin{array}{l}\mathrm{R} 6 / 5 \\
\mathrm{~L} 6 / 5\end{array}$ \\
\hline 6 & Straight & $\begin{array}{l}\text { R: }-0.50 \text { DS } \\
\text { L: }-0.50 \text { DS }\end{array}$ & $\begin{array}{l}\text { R 6/5 } \\
\text { L } 6 / 5\end{array}$ \\
\hline 7 & Straight & $\begin{array}{l}\mathrm{R}:-2 \cdot 50 /+4.00 \times 170 \\
\mathrm{~L}:-5 \cdot 00 /+2 \cdot 00 \times 170\end{array}$ & $\begin{array}{l}\text { R } 6 / 5 \\
\text { L } 6 / 5\end{array}$ \\
\hline 8 & Straight & $\begin{array}{l}\text { R:Plano } \\
\text { L:Plano }\end{array}$ & $\begin{array}{l}\text { R } 6 / 6 \\
\text { L } 6 / 5\end{array}$ \\
\hline 9 & Straight & $\begin{array}{l}\text { R: }-1.00 \text { DS } \\
\text { L: }-1.00 \text { DS }\end{array}$ & $\begin{array}{l}\text { R } 6 / 5 \\
\mathrm{~L} 6 / 5\end{array}$ \\
\hline 10 & Straight & $\begin{array}{l}\mathbf{R}:-3.75 /+0.75 \times 70 \\
\mathbf{L}:-3.75 /+0.50 \times 180\end{array}$ & $\begin{array}{l}\text { R } 6 / 6 \\
\text { L } 6 / 6\end{array}$ \\
\hline 11 & Straight & $\begin{array}{l}\text { R:Plano } \\
\text { L: }-0.25 /+0.50 \times 90\end{array}$ & $\begin{array}{l}\text { R } 6 / 5 \\
\text { L 6/5 }\end{array}$ \\
\hline 12 & Straight & $\begin{array}{l}\text { R: }-8 \cdot 50 /+0.50 \times 15 \\
\text { L: }-5 \cdot 75 \text { DS }\end{array}$ & $\begin{array}{l}\text { R } 6 / 5 \\
\text { L } 6 / 5\end{array}$ \\
\hline
\end{tabular}

during each 2 minute sequence of eye movements. Mean values were calculated for all the affected and unaffected eyes (amblyopes) and all the right and left eyes (controls). Comparisons were made using Student's two tailed paired $t$ test.

The mean values obtained from the amblyopic eyes were lower than those from the fellow normal eyes at all times in dark and light. The difference was significant $(p<0.05)$ in most cases as shown in Table 3. There was no difference between the mean values obtained from the right and left control eyes. The data from Table 3 are shown in Figures 1 and 2 .

In order to reduce the intersubject variation in the absolute values obtained, the results were normalised by expressing each value as a percentage of the maximum value obtained from the subject. The statistical comparisons between affected and unaffected eyes of the amblyopes, and the right and left eyes of the controls were then repeated using the normalised data. The results are shown in Table 4 which illustrates that the difference between the amblyopic and non-amblyopic eyes became significant at all times during the recording and the significance was increased. There remained no significant difference between the right and left eyes of the control subjects. The data from Table 4 are shown in Figures 3 and 4.

Further comparisons were carried out using the normalised data. The values from the amblyopic eyes were compared separately with those from either the right or left control eyes using Student's unpaired two tailed $t$ test. In all cases the mean values from the amblyopic eyes were significantly lower $(p<0.05)$ than those from the right or left control eyes. There was no significant difference between the values from the non-amblyopic eyes and either the right or left control eyes. As a further check, an analysis of variance (ANOVA) was performed to compare the normalised results from all four groups of eyes for the light peak and for the dark trough. There was a significant difference 
Table 3 Mean (SD) amplitude ( $\mu V)$ of EOG recordings from affected and non-affected eyes (amblyopes) and right and left eyes (controls)

\begin{tabular}{|c|c|c|c|c|c|c|c|}
\hline \multirow[b]{2}{*}{ Illumination } & \multirow{2}{*}{$\begin{array}{l}\text { Time } \\
\text { (minutes) }\end{array}$} & \multicolumn{3}{|c|}{ Amblyopes $(n=12)$} & \multicolumn{3}{|c|}{ Controls $(n=12)$} \\
\hline & & Affected $(\mu V)$ & p Value & Unaffected $(\mu V)$ & Right $(\mu V)$ & p Value & Left $(\mu V)$ \\
\hline $\begin{array}{l}\text { Dark } \\
\text { Dark } \\
\text { Dark } \\
\text { Dark } \\
\text { Dark } \\
\text { Dark } \\
\text { Light } \\
\text { Light } \\
\text { Light } \\
\text { Light } \\
\text { Light } \\
\text { Light } \\
\text { Light } \\
\text { Light } \\
\text { Light }\end{array}$ & $\begin{array}{r}0 \\
2 \\
4 \\
6 \\
8 \\
10 \\
12 \\
14 \\
16 \\
18 \\
20 \\
22 \\
24 \\
26 \\
28\end{array}$ & $\begin{array}{l}336(195) \\
304(200) \\
274(177) \\
249(160) \\
228(140) \\
216(130) \\
237(140) \\
325(195) \\
459(264) \\
536(305) \\
555(322) \\
518(310) \\
437(287) \\
352(241) \\
290(210)\end{array}$ & $\begin{array}{l}0.076 \\
0.007 \\
0.018 \\
0.030 \\
0.029 \\
0.044 \\
0.067 \\
0.066 \\
0.078 \\
0.047 \\
0.046 \\
0.039 \\
0.017 \\
0.028 \\
0.022\end{array}$ & $\begin{array}{l}367(191) \\
342(193) \\
314(183) \\
278(165) \\
255(144) \\
242(123) \\
267(134) \\
364(180) \\
508(255) \\
592(293) \\
613(309) \\
575(298) \\
495(290) \\
402(252) \\
335(222)\end{array}$ & $\begin{array}{l}411(114) \\
379(156) \\
344(104) \\
314(96) \\
290(100) \\
284(99) \\
307(93) \\
399(130) \\
523(156) \\
615(170) \\
641(178) \\
604(175) \\
528(167) \\
441(159) \\
378(140)\end{array}$ & $\begin{array}{l}0.85 \\
0.76 \\
0.61 \\
0.56 \\
0.70 \\
0.94 \\
0.79 \\
0.96 \\
0.71 \\
0.69 \\
0.56 \\
0.63 \\
0.34 \\
0.42 \\
0.61\end{array}$ & $\begin{array}{l}414(121) \\
384(119) \\
351(111) \\
322(106) \\
296(106) \\
285(106) \\
311(111) \\
399(120) \\
534(145) \\
623(169) \\
654(190) \\
614(187) \\
545(191) \\
455(178) \\
382(162)\end{array}$ \\
\hline
\end{tabular}

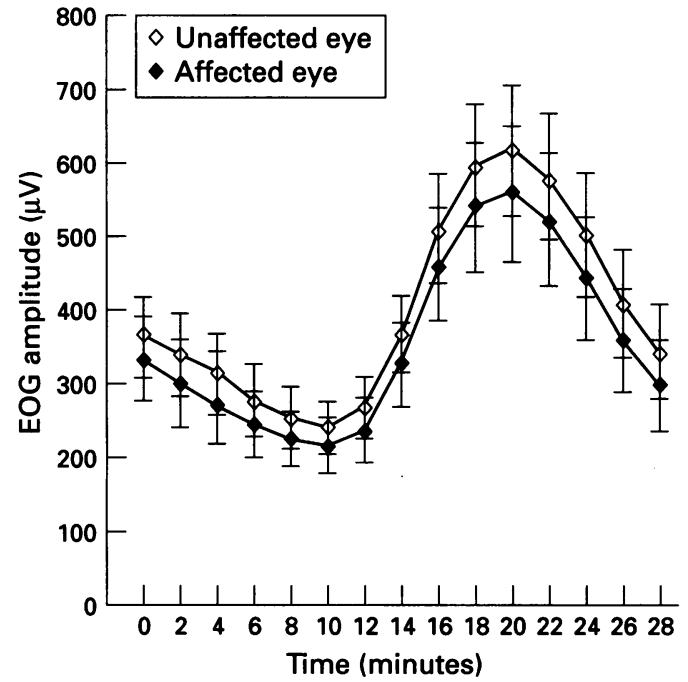

Figure 1 Mean (SE) EOG amplitude $(\mu V)$ for affected and unaffected eyes of amblyopic subjects.

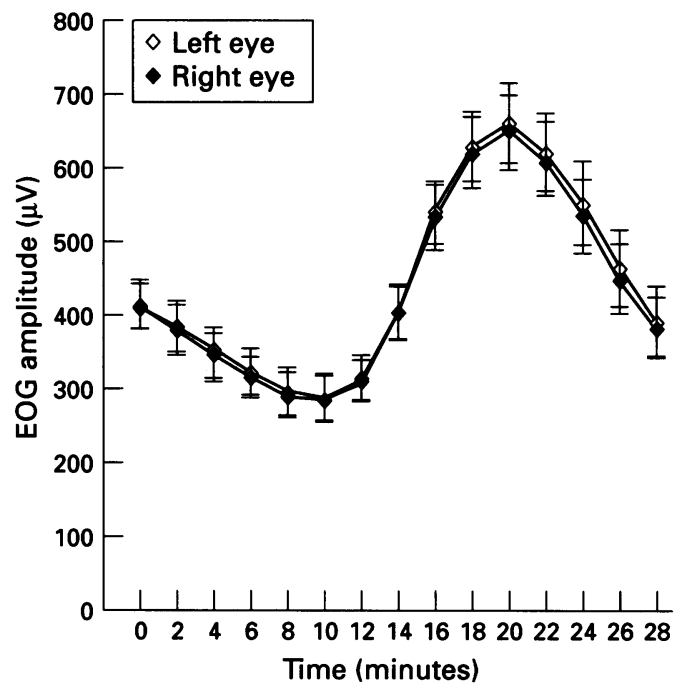

Figure 2 Mean (SE) EOG amplitudes $(\mu V)$ for right and left eyes of control subjects.

in the dark trough values between the four groups ( $F$ ratio $4 \cdot 943, \mathrm{p}=0 \cdot 005$ ). Tukey's pairwise comparison showed that the DT values from the amblyopic eyes were significantly lower than those from the right $(p=0.008)$ and left $(p=0.010)$ control eyes but not from the fellow eyes $(p=0 \cdot 172)$. There was also a significant difference in the light peak values between the four groups of eyes ( $F$ ratio 5.690, $\mathrm{p}=0.002)$. Tukey's pairwise comparison showed that the light peak values from the amblyopic eyes were significantly lower than those from the fellow eyes $(p=0.003)$, the right $(p=0.008)$ and left $(p=0.002)$ control eyes.

The light peak/dark trough ratio was calculated for each subject and was normal $(>170 \%)$ in all cases. The mean value for the amblyopic eyes was $216 \%$ (SD $130 \%$ ) and for the non-amblyopic eyes was $243 \%$ (SD $123 \%$ ), there was no significant difference $(p=0.43)$. Similarly the mean ratio for the control right eyes was $234 \%$ (SD $35 \%$ ) and for the left eyes was $241 \%$ (SD $45 \%$ ); there was no significant difference between them $(p=0 \cdot 45)$.

The time course of the EOG changes was normal in all subjects. The individual amplitudes of the dark trough, light peak and the time taken to reach these points for each subject are given in Table 5 for the dark trough and Table 6 for the light peak. The mean time until the dark trough was $9 \cdot 17$ minutes for amblyopic and fellow eyes; there was no significant difference (paired $t$ test, $\mathrm{p}=1 \cdot 0$ ). The corresponding times for the right and left eyes of the controls were right eye 8.50 minutes and left eye 9.33 minutes; there was again no significant difference $(p=0 \cdot 096)$. Similarly the mean time until the light peak was 19.50 minutes for the amblyopic, fellow and right control eyes and 19.67 minutes for the left control eyes. There was no significant difference in the time until light peak between the amblyopic and fellow eyes $(p=1 \cdot 0)$ or the right and left control eyes $(p=0.338)$.

The potential measured in the EOG is dependent on eye movement as well as on retinal function. The eye movements of all subjects were recorded on videotape as the EOG was being carried out. The eye movements were subsequently studied and measured using freeze frame examination of the videotape. The eye movements were measured on the screen from limbus to inner canthus at the point of maximal abduction of each eye. A mean of 4-6 measurements was calculated for each eye. The mean values were compared between amblyopic and fellow eyes for the amblyopes and the right and left eyes for the controls. There was no significant difference between the means for the amblyopic and fellow eyes $(p=0.50)$ or between the right and left eyes of the controls $(p=0 \cdot 17)$.

When looked at individually there were 
Table 4 Mean values (SD) obtained using normalised data (\% maximum from each subject) for EOG recordings from affected and non-affected eyes (amblyopes) and right and left eyes (controls)

\begin{tabular}{|c|c|c|c|c|c|c|c|}
\hline \multirow[b]{2}{*}{ Illumination } & \multirow{2}{*}{$\begin{array}{l}\text { Time } \\
\text { (minutes) }\end{array}$} & \multicolumn{3}{|c|}{ Amblyopes $(n=12)$} & \multicolumn{3}{|c|}{ Controls $(n=12)$} \\
\hline & & Affected $(\mu V)$ & p Value & Unaffected $(\mu V)$ & Right $(\mu V)$ & p Value & Left $(\mu V)$ \\
\hline $\begin{array}{l}\text { Dark } \\
\text { Dark } \\
\text { Dark } \\
\text { Dark } \\
\text { Dark } \\
\text { Dark } \\
\text { Light } \\
\text { Light } \\
\text { Light } \\
\text { Light } \\
\text { Light } \\
\text { Light } \\
\text { Light } \\
\text { Light } \\
\text { Light }\end{array}$ & $\begin{array}{r}0 \\
2 \\
4 \\
6 \\
8 \\
10 \\
12 \\
14 \\
16 \\
18 \\
20 \\
22 \\
24 \\
26 \\
28\end{array}$ & $\begin{array}{l}50 \cdot 7(9 \cdot 0) \\
44 \cdot 8(9 \cdot 7) \\
40 \cdot 4(8 \cdot 7) \\
37 \cdot 0(8 \cdot 2) \\
34 \cdot 3(7 \cdot 6) \\
32 \cdot 5(7 \cdot 0) \\
35 \cdot 1(8 \cdot 4) \\
48 \cdot 0(9 \cdot 8) \\
68 \cdot 7(12 \cdot 1) \\
80 \cdot 3(11 \cdot 8) \\
82 \cdot 9(13 \cdot 4) \\
77 \cdot 1(14 \cdot 0) \\
64 \cdot 3(16 \cdot 4) \\
51 \cdot 6(15 \cdot 6) \\
42 \cdot 3(14 \cdot 3)\end{array}$ & $\begin{array}{l}0.041 \\
0.041 \\
0.009 \\
0.013 \\
0.021 \\
0.034 \\
0.041 \\
0.044 \\
0.044 \\
0.029 \\
0.031 \\
0.029 \\
0.014 \\
0.020 \\
0.015\end{array}$ & $\begin{array}{l}57 \cdot 6(7 \cdot 9) \\
53 \cdot 2(7 \cdot 4) \\
48 \cdot 6(7 \cdot 8) \\
43 \cdot 1(7 \cdot 5) \\
39 \cdot 7(7 \cdot 0) \\
38 \cdot 4(7 \cdot 5) \\
42 \cdot 1(7 \cdot 0) \\
57 \cdot 1(9 \cdot 5) \\
79 \cdot 3(9 \cdot 8) \\
92 \cdot 6(7 \cdot 6) \\
95 \cdot 6(6 \cdot 2) \\
89 \cdot 6(7 \cdot 7) \\
76 \cdot 5(12 \cdot 6) \\
61 \cdot 7(13 \cdot 9) \\
51 \cdot 1(12 \cdot 8)\end{array}$ & $\begin{array}{l}61 \cdot 4(8 \cdot 0) \\
56 \cdot 1(7 \cdot 4) \\
50 \cdot 8(6 \cdot 2) \\
46 \cdot 5(5 \cdot 6) \\
42 \cdot 6(5 \cdot 8) \\
41 \cdot 7(6 \cdot 1) \\
45 \cdot 5(6 \cdot 3) \\
58 \cdot 7(8 \cdot 9) \\
78 \cdot 0(7 \cdot 7) \\
91 \cdot 3(7 \cdot 8) \\
95 \cdot 1(6 \cdot 9) \\
89 \cdot 5(8 \cdot 5) \\
77 \cdot 9(9 \cdot 1) \\
64 \cdot 6(9 \cdot 8) \\
54.6(9 \cdot 2)\end{array}$ & $\begin{array}{l}0.98 \\
0.78 \\
0.65 \\
0.62 \\
0.68 \\
0.92 \\
0.96 \\
0.95 \\
0.64 \\
0.68 \\
0.59 \\
0.68 \\
0.41 \\
0.51 \\
0.76\end{array}$ &  \\
\hline
\end{tabular}

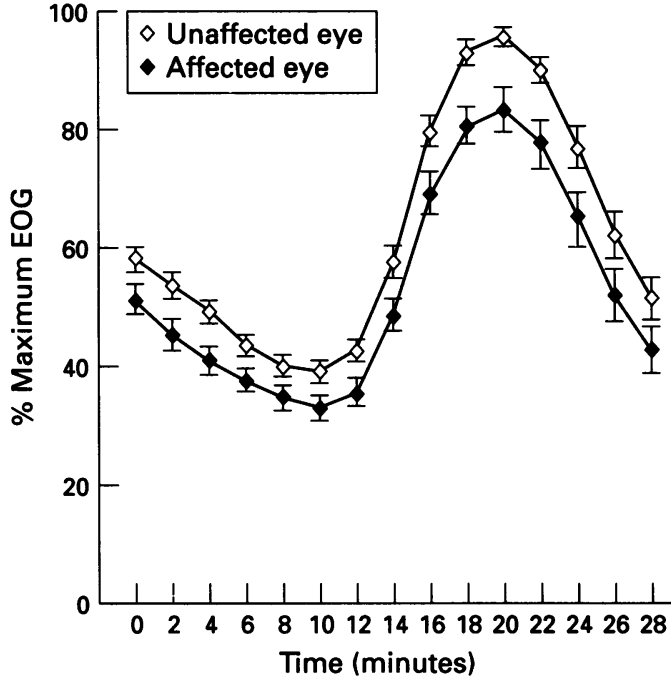

Figure 3 Mean (SE) normalised EOG amplitudes for affected and unaffected eyes of amblyopic subjects.



Figure 4 Mean (SE) normalised EOG amplitudes for right and left eyes of control subjects.

interocular differences in EOG amplitude for most of the control subjects as well as for the amblyopes. Nine of the amblyopes had recordings consistently smaller from their amblyopic eyes, two had recordings consistently greater from their amblyopic eyes, and for one there was no difference between the eyes. In the control group, five control subjects had recordings consistently smaller from their left eyes, six had recordings consistently lower in their right eyes, and for one subject there was no difference between the eyes. In order to explore the interocular variation for all subjects, a mean value of the interocular difference ('IOD index') for all 15 recordings was calculated for each subject $(\mathrm{R}-\mathrm{L} / \mathrm{R} \%$ for the controls and non-affected-affected/nonaffected \% for the amblyopes). These values are shown in Figures 5 and 6. The mean IOD index for the control subjects was $-2 \cdot 12 \%$ (SD $13.27 \%$ ) and for the amblyopes was $13.52 \%$ (SD 20.02\%). A one sample $t$ test was carried out on the IOD indices for the control group and the mean was not significantly different from $0(p=0 \cdot 59)$. The same test carried out on the IOD indices from the amblyopes shows that the mean is significantly different from $0(p=0 \cdot 015)$.

The data from the normal subjects can be used as a normal range with which to compare the values from the amblyopes. Five amblyopes have IOD indices greater than 2 SD from the control group mean; all such that the affected eye has smaller EOG amplitudes. The amblyopes with an abnormally large IOD index were subjects $2,3,5,6$, and 9 . If the individual values for IOD in the light peak are considered in the same way (NA-ANA\% for the amblyopes and $\mathbf{R}-\mathbf{L} / \mathbf{R} \%$ for the controls) a similar distribution is seen. The same five amblyopes have an IOD in the LP values greater than $2 \mathrm{SD}$ from the control mean. There was more variability in the DT values such that only three amblyopes had DT IOD outside $2 \mathrm{SD}$ of the control group mean (subjects 3, 8, and 9).

The normalised data were used to compare DT and LP with the visual acuity for the amblyopic eyes. Such a comparison would be inappropriate for the unaffected eyes or the control subjects' eyes as all visual acuities were normal. Correlation coefficients for the logarithm of the reciprocal of the Snellen acuity compared with the DT $(r=-0.37)$ or the LP $(r=0.0045)$ were not statistically significant, although a trend was observed towards worse visual acuities being associated with lower DT values.

\section{Discussion}

The results from this study demonstrate that the normalised mean EOG amplitudes 
Table 5 Individual dark trough (DT) amplitudes ( $\mu V)$ and time to $D T$ (minutes) for all subjects

\begin{tabular}{|c|c|c|c|c|c|c|c|c|c|c|c|}
\hline $\begin{array}{l}\text { Amblyope } \\
\text { number }\end{array}$ & $\begin{array}{l}\text { Aff } D T \\
(\mu V)\end{array}$ & $\begin{array}{l}\text { Time } \\
\text { (minutes) }\end{array}$ & Palue & $\begin{array}{l}U_{D T} T^{\prime}(\mu V) \\
\end{array}$ & $\begin{array}{l}\text { Time } \\
\text { (minutes) }\end{array}$ & $\begin{array}{l}\text { Control } \\
\text { number }\end{array}$ & $\begin{array}{l}\text { Right } \\
D T(\mu V)\end{array}$ & $\begin{array}{l}\text { Time } \\
\text { (minutes) }\end{array}$ & Palue & $\begin{array}{l}\text { Left DT } \\
(\mu V)\end{array}$ & $\begin{array}{l}\text { Time } \\
\text { (minutes) }\end{array}$ \\
\hline $\begin{array}{r}1 \\
2 \\
3 \\
4 \\
5 \\
6 \\
7 \\
8 \\
9 \\
10 \\
11 \\
12\end{array}$ & $\begin{array}{r}321 \\
150 \\
112 \\
237 \\
125 \\
87 \\
312 \\
125 \\
87 \\
237 \\
537 \\
250\end{array}$ & $\begin{array}{r}10 \\
12 \\
6 \\
8 \\
6 \\
8 \\
10 \\
12 \\
10 \\
8 \\
10 \\
10\end{array}$ & & $\begin{array}{l}325 \\
200 \\
175 \\
175 \\
175 \\
112 \\
337 \\
200 \\
150 \\
237 \\
575 \\
225\end{array}$ & $\begin{array}{r}10 \\
8 \\
6 \\
10 \\
8 \\
10 \\
8 \\
12 \\
8 \\
10 \\
10 \\
10\end{array}$ & $\begin{array}{r}1 \\
2 \\
3 \\
4 \\
5 \\
6 \\
7 \\
8 \\
9 \\
10 \\
11 \\
12\end{array}$ & $\begin{array}{l}162 \\
200 \\
475 \\
337 \\
162 \\
287 \\
275 \\
262 \\
300 \\
375 \\
187 \\
375\end{array}$ & $\begin{array}{r}10 \\
8 \\
6 \\
8 \\
8 \\
8 \\
10 \\
10 \\
8 \\
10 \\
8 \\
8\end{array}$ & & $\begin{array}{l}162 \\
225 \\
487 \\
312 \\
150 \\
300 \\
387 \\
162 \\
300 \\
325 \\
187 \\
412\end{array}$ & $\begin{array}{r}10 \\
10 \\
10 \\
8 \\
10 \\
10 \\
8 \\
10 \\
8 \\
10 \\
10 \\
8\end{array}$ \\
\hline $\begin{array}{l}\text { Mean } \\
\text { SD }\end{array}$ & & $\begin{array}{l}9 \cdot 17 \\
1.99\end{array}$ & 1.0 & & $\begin{array}{l}9 \cdot 17 \\
1.59\end{array}$ & & & $\begin{array}{l}8 \cdot 50 \\
1 \cdot 24\end{array}$ & 0.096 & & $\begin{array}{l}9.33 \\
0.98\end{array}$ \\
\hline
\end{tabular}

obtained from a group of amblyopic eyes were significantly lower that the normalised mean amplitudes from the fellow eyes at all time points during the EOG recording. There was no significant difference at any time point between the right and left eyes of age and sex matched controls who underwent an identical recording procedure. The reduction in EOG amplitude was consistent in all conditions of light and dark adaptation tested. This is illustrated by the fact that the LP/DT ratios for all subjects were normal. In the nine out of 12 amblyopes who had reduced EOG amplitudes in their affected eyes, the DT and the LP were equally affected, therefore the LP/DT ratio remained normal. From the available clinical information on the amblyopes there are no distinguishing features to explain why the other three were different. There was no significant correlation between the LP amplitude and visual acuity, refractive error, or treatment history. It may be that the normal intersubject and intrasubject variation is too great to allow the observation of subtle differences between subjects, or that too little information is available on the presenting features and treatment history of the amblyopes. The amblyopes were mainly anisometropic or mixed anisometro$\mathrm{pic} / \mathrm{microstrabismic}$. This was due to the inclusion criterion specifying no previous ocular surgery, as it was suspected that surgery would have resulted in abnormal eye movements which would affect the EOG. The amblyopic group, however, is heterogeneous with respect to the aetiology of their amblyopia. The two amblyopes who had larger EOG amplitudes in their affected eyes (amblyopes 4 and 12) were both straight eyed anisometropes, as was the amblyope whose EOG amplitudes were equal in both eyes (amblyope 10). Amblyopes 4 and
10 had received occlusion therapy with some improvement in visual acuity, but amblyope 12 had no recollection of any occlusion and no medical notes were available to exclude other forms of treatment such as atropinisation. It has been suggested that previous partially successful treatment of amblyopia can result in increased amplitude PERGs in the affected eyes. ${ }^{519}$ It may be that previous treatment is a relevant factor in the atypical results from amblyopes 4,10 , and 12 , but we do not have adequate previous records to assess this possibility fully.

In our results the LP values (both actual and normalised) show less variability between subjects than do the DT values. This phenomenon was also described by Anderson and Purple in their paper on circadian rhythms and variability in the clinical EOG. ${ }^{20}$ They suggest that this may reflect the dose dependent relation of the LP to the level of illumination and the period of dark adaptation, both of which are fixed in the procedure for recordings. The DT, however, is an absolute value for each individual and displays a diurnal fluctuation. While diurnal changes would not affect interocular differences, they may explain the greater variability in DT values. However, all recordings were carried out in normal working hours and not at the times of the most pronounced diurnal changes, which occur in the late evening and early morning. Other sources of error such as variations in facial asymmetry, electrode placement, and measurement error affect both the recordings from the amblyopes and from the controls. These errors cannot explain the significant interocular difference between the amblyopic and non-amblyopic eyes, as there is no such difference between the control eyes. Asymmetry of eye movements

Table 6 Individual light peak (LP) amplitudes ( $\mu V)$ and time to LP (minutes) for all subjects

\begin{tabular}{|c|c|c|c|c|c|c|c|c|c|c|c|}
\hline $\begin{array}{l}\text { Amblyope } \\
\text { number }\end{array}$ & $\begin{array}{l}A f f L P \\
(\mu V)\end{array}$ & $\begin{array}{l}\text { Time } \\
\text { (minutes) }\end{array}$ & Palue & $\begin{array}{l}\text { Unaff } \\
L P(\mu V)\end{array}$ & $\begin{array}{l}\text { Time } \\
\text { (minutes) }\end{array}$ & $\begin{array}{l}\text { Control } \\
\text { number }\end{array}$ & $\begin{array}{l}\text { Right } \\
L P(\mu V)\end{array}$ & $\begin{array}{l}\text { Time } \\
\text { (minutes) }\end{array}$ & Palue & $\begin{array}{l}\text { Left } L P \\
(\mu V)\end{array}$ & $\begin{array}{l}\text { Time } \\
\text { (minutes) }\end{array}$ \\
\hline $\begin{array}{r}1 \\
2 \\
3 \\
4 \\
5 \\
6 \\
7 \\
8 \\
9 \\
10 \\
11 \\
12\end{array}$ & $\begin{array}{r}662 \\
300 \\
300 \\
600 \\
275 \\
275 \\
812 \\
387 \\
262 \\
887 \\
1300 \\
700\end{array}$ & $\begin{array}{l}22 \\
20 \\
18 \\
20 \\
18 \\
18 \\
20 \\
20 \\
20 \\
18 \\
20 \\
20\end{array}$ & & $\begin{array}{r}687 \\
437 \\
450 \\
487 \\
362 \\
375 \\
925 \\
475 \\
387 \\
850 \\
1430 \\
612\end{array}$ & $\begin{array}{l}22 \\
20 \\
18 \\
20 \\
20 \\
18 \\
18 \\
20 \\
20 \\
18 \\
20 \\
20\end{array}$ & $\begin{array}{r}1 \\
2 \\
3 \\
4 \\
5 \\
6 \\
7 \\
8 \\
9 \\
10 \\
11 \\
12\end{array}$ & $\begin{array}{l}387 \\
425 \\
875 \\
712 \\
400 \\
600 \\
862 \\
712 \\
662 \\
837 \\
487 \\
800\end{array}$ & $\begin{array}{l}20 \\
18 \\
20 \\
18 \\
20 \\
20 \\
22 \\
18 \\
18 \\
20 \\
20 \\
20\end{array}$ & & $\begin{array}{l}387 \\
525 \\
912 \\
700 \\
387 \\
650 \\
962 \\
600 \\
675 \\
750 \\
475 \\
887\end{array}$ & $\begin{array}{l}20 \\
18 \\
20 \\
18 \\
20 \\
20 \\
22 \\
18 \\
20 \\
20 \\
20 \\
20\end{array}$ \\
\hline $\begin{array}{l}\text { Mean } \\
\text { SD }\end{array}$ & & $\begin{array}{r}19 \cdot 50 \\
1 \cdot 24\end{array}$ & 1.00 & & $\begin{array}{r}19 \cdot 50 \\
1.24\end{array}$ & & & $\begin{array}{r}19 \cdot 50 \\
1 \cdot 24\end{array}$ & 0.34 & & $\begin{array}{r}19 \cdot 67 \\
1.15\end{array}$ \\
\hline
\end{tabular}




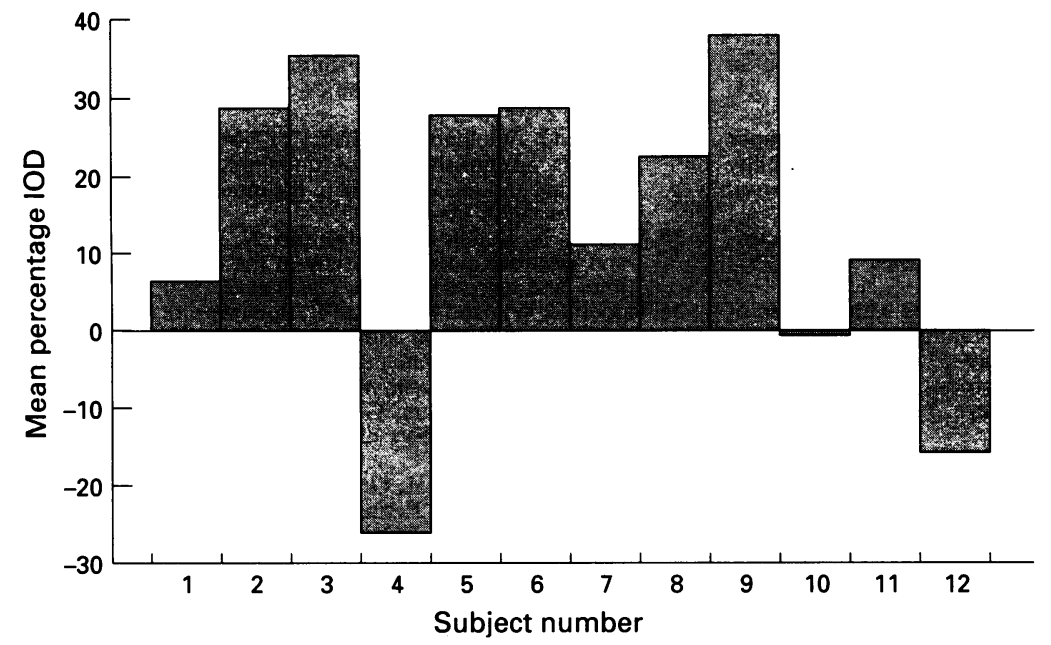

Figure 5 IOD indices for the amblyopic subjects.

could cause abnormalities of the EOG, but there was no significant difference between the degree of excursion of the amblyopic eyes compared with the normal fellow eyes. Abnormal drift in eye movements has been described in amblyopic eyes during monocular fixation but movements were normal during binocular fixation. ${ }^{21}$

The consistency of our results during dark and light adaptation suggests the involvement of the RPE, which is the main generator of the SP. Abnormal RPE function in amblyopia could be either a primary retinal phenomenon or secondary to central influences. There is little direct evidence of a corticofugal retinal input in mammals, although this has been well described in birds, fish, and reptiles. ${ }^{22} \mathrm{~A}$ primary retinal abnormality could involve the RPE or any part of the retina which affects RPE function. Dopamine has been proposed as affecting the changes in the depolarisation of the RPE which leads to the LP. ${ }^{13}$ This is based on observations that dopamine causes a dose dependent increase in the SP in both the perfused mammalian eye ${ }^{23}$ and the intact chicken eye. ${ }^{1324}$ These effects are blocked by halo-

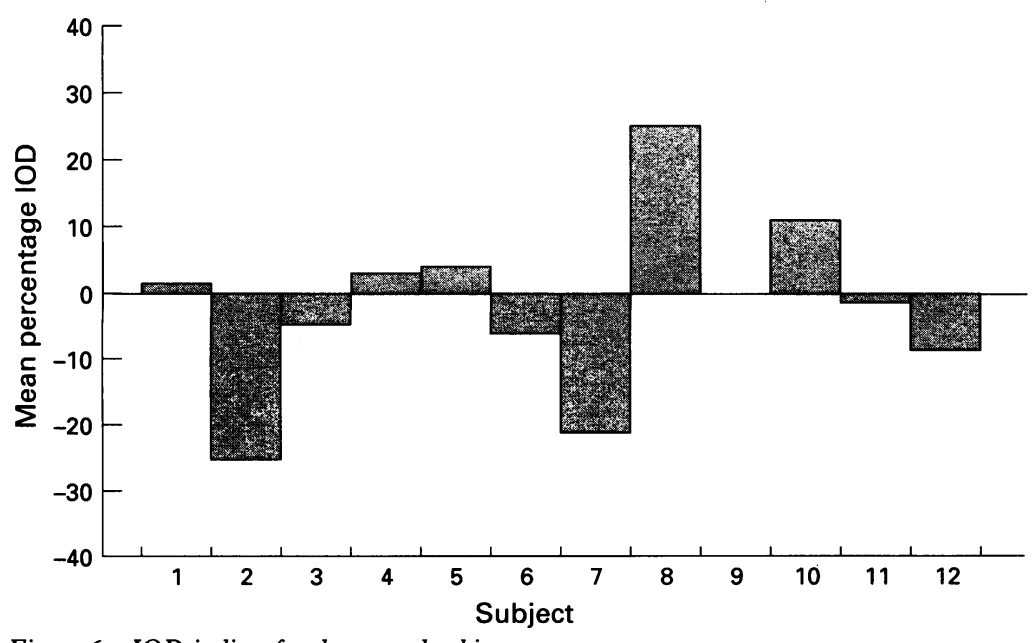

peridol. ${ }^{25}$ After blockade of catecholamine and serotonin synthesis an increase in the SP occurs in the chicken eye, suggesting that the SP may be affected by a balance between catecholamines and indolamine. ${ }^{26}$ Furthermore, the EOG is reported to be abnormal in cases of dopaminergic loss such as Parkinson's disease $^{27}$ and in depression. ${ }^{28-30}$ Dopamine levels in the retina exhibit a diurnal fluctuation with peak levels in the day and reduced levels at night. ${ }^{31}$ The SP similarly has a diurnal periodicity with the greatest dark adapted potentials being those recorded between 1230 and 1430. 20

Dopamine has already been implicated in the pathophysiology of human amblyopia. Dopamine improves visual function in amblyopic adults ${ }^{1632}$ and children. ${ }^{17}$ Thus, one can hypothesise that in human infants and children, retinal dopaminergic elements may be affected by visual abnormalities during the sensitive period of visual development. There is experimental evidence in support of this from animal models of amblyopia in which levels of retinal dopamine and tyrosine hydroxylase are reduced in the amblyopic eye. ${ }^{33-35}$ The visual deficits in amblyopia are more marked in photopic conditions when retinal dopamine activity should be high. As dopamine improves both visual function and increases the SP, a reduction in dopaminergic retinal function in amblyopia would fit with the experimental and clinical evidence, as well as the results of this study. Against this hypothesis, it has been shown that a large dose of levodopa caused a reduction in the DT in subjects with normal vision. ${ }^{14}$ However, the use of a peripheral decarboxylase inhibitor would have prevented the RPE cells from receiving any extra dopamine from the choroidal circulation. It may be also that the effects of levodopa on the human EOG vary with different doses as they do in the animal models.

Our findings demonstrate that the EOG is abnormal in some amblyopic subjects. Further work is necessary to characterise these findings in more detail and in a larger, more uniform sample, but our results support a retinal abnormality in amblyopia and the literature suggests that dopaminergic mechanisms may be involved.

This work was supported by the Special Trustees of UBHT whose help is gratefully acknowledged. The authors would also like to thank $\mathrm{Mr} \mathrm{J} \mathrm{C}$ Dean-Hart for his advice, $S$ Papakostopoulos for her help, and all the subjects who took part in the study.

1 Ikeda $\mathrm{H}$, Tremain KE. Amblyopia occurs in retinal ganglion cells in cats reared with convergent squint without alternating fixation. Exp Brain Res 1979; 35: 559-82.

2 Ikeda H, Wright MJ. Properties of LGN cells in kittens reared with convergent squint: a neurophysiological demonstration of amblyopia. Exp Brain Res 1976; 25: 63-77.

3 Devlin ML, Jay JL, Morrison JD. Abnormality of the pattern electroretinogram and pattern visual evoked cortical response in esotropic cats. Doc Ophthalmol 1989; 73: 53-69.

4 Baro JA, Lehmkuhle S, Kratz KE. Electroretinograms and visual evoked potentials in long-term monocularly deprived cats. Invest Ophthalmol Vis Sci 1990; 31: 1405-9.

5 Arden GB, Vaegan, Hogg CR, Powell DJ, Carter RM. Pattern ERGs are abnormal in many amblyopes. Trans Ophthalmol Soc UK 1980; 100: 453-60.

6 Persson HE, Wanger P. Pattern-reversal electroretinograms in squint amblyopia, artificial anisometropia and simulated eccentric fixation. Acta Ophthalmol 1982; 60: 123-32.

Figure 6 IOD indices for the control subjects. 
7 Arden GB, Wooding SL. Pattern ERG in amblyopia Invest Ophthalmol Vis Sci 1985; 26: 88-96.

8 Hess RF, Baker CL. Assessment of retinal function in severely amblyopic individuals. Vision Res 1984; 24: 1367-76.

9 Hess RF, Baker CL Jr, Verhoeve JN, Keesey UT, France TD. The pattern evoked electroretinogram: its variability in normals and its relationship to amblyopia. Invest Ophthalmol Vis Sci 1985; 26: 1610-23.

10 Gottlob I, Welge-Lussen L. Normal pattern electroretinograms in amblyopia. Invest Ophthalmol Vis Sci 1987 28: $187-91$.

11 Arden GB, Barrada A, Kelsey JH. New clinical test of retinal function based upon the standing potential of the eye. Br F Ophthalmol 1962; 46: 449-67.

12 Arden GB, Kelsey JH. Changes produced by light in the standing potential of the human eye. $\mathcal{F}$ Physiol 1962; 161: 189-204.

13 Rudolf G, Wioland N, Allart I. Is dopamine involved in the generation of the light peak in the intact chicken eye? Vision Res 1991; 11: 1841-9.

14 Gottlob I, Strenn K. Effect of levadopa on the human electrooculogram. Clin Vision Sci 1990; 5: 299-306.

15 Corbe C, Arnaud F, Brault Y, Janiak-Bolzinger C. Effect of a dopaminergic agonist, piribendil (Travastal $50 \mathrm{mg} \mathrm{LP}$ ) on visual and spatial integration in elderly subjects. f Neurol 1992; 239 (suppl 1): S22-7.

16 Gottlob I, Charlier J, Reinecke RD. Visual acuities and scotomas after one week levadopa administration in human amblyopia. Invest Ophthalmol Vis Sci 1992; 33: human $2722-8$.

17 Leguire LE, Rogers GL, Bremer DL, Walson P, Wali N. Levadopa treatment for childhood amblyopia. Invest Ophthalmol Vis Sci 1991; ARVO suppl: 820 .

18 Leguire LE, Walson PD, Rogers GL, Bremer DL McGregor ML. Longitudinal study of levadopa carbidopa for childhood amblyopia. $\mathcal{F}$ Pediatr Ophthalmol Strabismus 1993; 30: 354-60.

19 Arden GB, Vaegan, Hogg CR. Clinical and experimental evidence that the pattern electroretinogram (PERG) is generated in more proximal retinal layers than the vocal electroretinogram (FERG). Ann NY Acad Sci 1982; 388: 580-601.

20 Anderson $M L$, Purple RL. Circadian rhythms and variability of the clinical electro-oculogram. Invest Ophthalmol Vis Sci 1980; 19: 278-88.

21 Ciuffreda KJ, Kenyon RV, Stark L. Increased drift in amblyopic eyes. $\mathrm{Br}$ F Ophthalmol 1980; 64: 7-14.
22 Uchiyama $H$. Centrifugal pathways to the retina: influence of the optic tectum. Vis Neurosci 1989; 3: 183-206.

23 Dawis S, Niemeyer G. Dopamine influences the light peak in the perfused mammalian eye. Invest Ophthalmol Vis Sci 1986; 27: $330-5$.

24 Rudolf G, Wioland N. Effects of intravitreal and intravenous administrations of dopamine on the standing potential and the light peak in the intact chicken eye. Curr Eye Res 1990; 11: 1077-82.

25 Wioland N, Rudolf G, Bonaventure N. Electrooculographic and electroretinographic study in the chicken after dopamine and haloperidol. Doc Ophthalmol 1990; 75: 175-80.

26 Rudolf G, Wioland N, Kempf E, Bonaventure N. EOG and ERG modifications induced in the chicken eye after blockade of catecholamine and 5-hydroxytryptamine biosynthesis. Doc Ophthalmol 1990; 76: 47-53.

27 Economou SG, Stefanis CN. Changes of electrooculogram (EOG) in Parkinson's disease. Acta Neurol Scand 1987; 58: 44-52.

28 Seggie J, Macmillan H, Griffith L, Shannon HS, Martin J, Simpson $\mathrm{T}$, et al. Retinal pigment epithelium response and the use of the EOG and Arden ratio in depression. Psychiatr Res 1991; 36: 175-85.

29 Lam RW, Beattie CW, Buchanan A, Remick RA, Zis AP Low electrooculographic ratios in patients with seasonal affective disorder. Am 7 Psychiatry 1991; 148: 1526-9.

30 Papakostopoulos D, Harrison G. The electro-oculogram and depressive illness. Greek Ann Ophthalmol 1981; 18: 143-51.

31 Zawilska J, Nowak JZ. Regulation of melatonin biosynthesis in vertebrate retina: involvement of dopamine in the in vertebrate retina: involvement of dopamine in the 29: $3-14$.

32 Gottlob I, Stangler-Zuschrott E. Effect of levadopa on contrast sensitivity and scotomas in human amblyopia. Invest Ophthalmol Vis Sci 1990; 31: 776-80.

33 Iuvone PM, Tigges M, Fernandes A, Tigges J. Dopamine synthesis and metabolism in rhesus monkey retina: development, ageing and effects of monocular visual deprivation. Vis Neurosci 1989; 2: 465-71.

34 Spira AW, Parkinson D. Effects of dark-rearing on the retinal dopaminergic system in the neonatal and postnatal guinea pig. Dev Brain Res 1991; 62: 142-5.

35 Bartmann M, Schaeffel F, Zrenner E. The effects of constant light on retinal dopamine levels, form deprivation myopia and lens induced changes in eye growth in tion myopia and lens induced changes in eye growth in
chickens. Invest Ophthalmol Vis Sci 1993; ARVO suppl; 2492: 1210 . 